\title{
EDUCAÇÃO ESPECIAL E LÍNGUA BRASILEIRA DE SINAIS NA FORMAÇÃO DE PROFESSORES DO CAMPO
}

\author{
Jaqueline Daniela Basso ${ }^{1}$, Celi Corrêa Neres ${ }^{2}$
}

\begin{abstract}
${ }^{1}$ Doutora em Educação pela Universidade Federal de São Carlos - UFScar. Professora na Universidade Estadual de Mato Grosso do Sul- UEMS, Unidade Campo Grande, MS. Pesquisadora no Grupo de Estudos e Pesquisa em Educação do Campo da Universidade Federal de São Carlos - GEPEC/ UFSCar e no Grupo Trabalho, Educação e Políticas Públicas G-TEPE/UEMS. ORCID iD: https://orcid.org/0000-0002-4262-4140. E-mail: jaquelinebassoeec@gmail.com

${ }^{2}$ Doutora em Educação pela Universidade DE São Paulo - USP. Vice-reitora e Professora na Universidade Estadual de Mato Grosso do Sul- UEMS, Unidade Campo Grande, MS. do Grupo de Pesquisa em Educação Especial/ e do GEPSE/ HISTEBR/UEMS. ORCID iD: https://orcid.org/0000-0001-9864-2180. E-mail: c.neres@uol.com.br
\end{abstract}

\section{RESUMO}

A Educação Especial é direito de todos os educandos com algum tipo de deficiência; transtorno global ou altas habilidades/superdotação, modalidade presente em todas as etapas da escolarização brasileira, da creche às universidades, independentemente de onde a escola esteja localizada. Portanto, a Educação Especial deve se efetivar tanto em escolas urbanas quanto em escolas do campo. Quanto ao atendimento educacional especializado dos alunos surdos, ele deve ser bilíngue, em Língua Brasileira de sinais e em Língua Portuguesa. Assim, objetivamos neste estudo refletir acerca da interface entre educação especial e educação do campo com ênfase na inclusão da Libras como componente curricular obrigatório nos cursos de formação docente para professores do campo. Para alcançar este objetivo, valemo-nos de revisão bibliográfica, bem como de análise documental de parte da legislação que rege a Educação Especial e de um estudo de caso de cunho qualiquantitativo de um Curso Especial de Licenciatura em Pedagogia da Terra por meio da análise documental de seu Projeto Político Pedagógico e questionário aplicado a uma amostra de seus egressos. Concluímos que a inclusão da disciplina Libras nas licenciaturas representa um ganho para a comunidade surda e a possibilidade de formar professores conscientes de sua importância para a escolarização bilíngue dos alunos surdos e dos direitos educacionais destes alunos. Entretanto, não se mostrou suficiente para tornar os futuros professores proficientes em Libras, nesse sentido, sugerimos como possibilidades de aperfeiçoamento o aumento da carga horária da disciplina nos cursos, seu aprofundamento em projetos de ensino e extensão e apontamos para a necessidade de mais pesquisas na área.

Palavras-chave: Educação Especial. Educação do Campo. Língua Brasileiras de Sinais. Formação de Professores. Pedagogia da Terra.

\section{SPECIAL EDUCATION AND BRAZILIAN SIGN LANGUAGE IN THE TRAINING OF FIELD TEACHERS}

\begin{abstract}
Special Education is the right of all students with some type of disability; global disorder or high skills / giftedness, a modality present in all stages of Brazilian schooling, from day care to universities, regardless of where the school is located. Therefore, Special Education must take place both in urban schools and in rural schools. As for the specialized educational assistance of deaf students, he must be bilingual, in Brazilian Sign Language and Portuguese Language. Thus, in this study we aim to reflect on the interface between special education and rural education with an emphasis on the inclusion of Libras as a mandatory curricular component in teacher training courses for rural teachers. In order to achieve this objective, we use a bibliographic review; documentary analysis of part of the legislation governing Special Education and a case study of a qualitative and quantitative nature of a Special Degree Course in Pedagogy of the Earth through the documentary analysis of its Political Pedagogical Project and a questionnaire applied to a sample of its students. graduates. We conclude that the inclusion of the Libras discipline in undergraduate
\end{abstract}


courses represents a gain for the deaf community and the possibility of training teachers aware of its importance for the bilingual schooling of deaf students and the educational rights of these students. However, it has not proved to be sufficient to make future teachers proficient in Libras, in this sense we suggest as possibilities the increase in the course load of courses, their deepening in teaching and extension projects and we point to the need for more research in the area.

Keywords: Special education. Rural Education. Brazilian Sign Language. Teacher training. Field Pedagogy.

\section{EDUCACIÓN ESPECIAL Y LENGUA BRASILEÑA DE SIGNOS EN LA FORMACIÓN DE DOCENTES RURALES}

\section{RESUMEN}

La educación especial es el derecho de todos los estudiantes con algún tipo de discapacidad; trastorno global o altas habilidades / superdotación, una modalidad presente en todas las etapas de la escolaridad brasileña, desde la guardería hasta las universidades, independientemente de dónde se encuentre la escuela. Por lo tanto, la educación especial debe tener lugar tanto en las escuelas urbanas como en las rurales. En cuanto a la asistencia educativa especializada de los estudiantes sordos, debe ser bilingüe, en lenguaje de señas brasileño y portugués. Por lo tanto, nuestro objetivo en este estudio es reflexionar sobre la interfaz entre la educación especial y la educación rural con énfasis en la inclusión de Libras como un componente curricular obligatorio en los cursos de capacitación docente para maestros rurales. Para lograr este objetivo, utilizamos una revisión bibliográfica; análisis documental de parte de la legislación que rige la Educación Especial y un estudio de caso de naturaleza cualitativa y cuantitativa de un Curso Especial en Pedagogía de la Tierra a través del análisis documental de su Proyecto Pedagógico Político y un cuestionario aplicado a una muestra de sus estudiantes. graduados Concluimos que la inclusión de la disciplina de Libra en los cursos de pregrado representa una ganancia para la comunidad sorda y la posibilidad de capacitar a los maestros conscientes de su importancia para la escolarización bilingüe de los estudiantes sordos y los derechos educativos de estos estudiantes. Sin embargo, no ha demostrado ser suficiente para que los futuros docentes sean competentes en Libras, en este sentido sugerimos como posibilidades el aumento en la carga de cursos, su profundización en proyectos de enseñanza y extensión y señalamos la necesidad de más investigación en el área.

Palabras clave: Educación especial. Educación rural. Lengua Brasileña de signos. Formación de profesores. Pedagogía de la tierra.

\section{INTRODUÇÃO}

A Educação Especial nas escolas regulares é prevista no capítulo $V$ da Lei n. 9.394/96, que estabelece as Diretrizes e Bases da Educação Nacional, que prediz, dentre outras coisas, a adequação na formação docente e serviços de apoio quando necessário. No caso da escolarização dos alunos com deficiência auditiva é necessário que ela seja bilíngue, isto é, feita por meio da Língua Brasileira de Sinais e da Língua Portuguesa. O que torna essencial a presença da Língua Brasileira de Sinais - Libras nos cursos de formação de professores.

Entendida enquanto modalidade que perpassa todas as etapas da escolarização brasileira, da creche às universidades, a Educação Especial é direito de todos os educandos com algum tipo de deficiência; transtorno global ou altas habilidades/superdotação, independentemente de onde a escola esteja localizada. Portanto, a Educação Especial deve se efetivar tanto em escolas urbanas quanto em escolas do campo. Quanto ao atendimento educacional especializado dos alunos surdos, ele deve ser bilíngue, em Língua Brasileira de sinais e em Língua Portuguesa.

Assim, objetivamos neste estudo refletir acerca da interface entre educação especial e educação do campo com ênfase na inclusão da Libras como componente curricular obrigatório nos cursos de formação docente para professores do campo. Para alcançar este objetivo, valemonos de revisão bibliográfica a partir de produções acadêmicas da área; bem como de análise documental de parte da legislação que rege a Educação Especial e de um estudo de caso de cunho qualiquantitativo de um Curso Especial de Licenciatura em Pedagogia da Terra por meio da análise documental de seu Projeto Político Pedagógico e questionário aplicado a uma amostra dos egressos das duas turmas nele formadas. 
A pesquisa foi realizada por duas professoras doutoras e motivada por suas experiências profissionais, tanto em um curso de Licenciatura em Pedagogia da Terra, quanto na ministração da disciplina "Tópicos em Educação Especial" em uma Universidade Estadual, que colocaram em relevo a importância e necessidade de maiores estudos sobre a temática aqui proposta.

Iniciaremos a exposição dos resultados discutindo a interface entre a Educação Especial e a Educação do Campo, dando destaque ao fato de serem demandas sociais incluídas nas agendas públicas com maior ênfase no início dos anos 2000, período que podemos considerar recente se avaliarmos todo o histórico da educação pública no Brasil. Em seguida nos dedicaremos à Libras na formação de professores, à formação de professores para o campo e, por fim, ao caso de um Curso Especial de Licenciatura em Pedagogia da Terra que nos permitirá compreender os limites e as possibilidades de inclusão da Libras enquanto disciplina da grade curricular dos cursos de formação docente.

\section{EDUCAÇÃO ESPECIAL E EDUCAÇÃO DO CAMPO: UMA INTERFACE NECESSÁRIA}

A política de educação especial pressupõe que os alunos com deficiência sejam matriculados nas escolas regulares, oferecendo as condições físicas, materiais e de formação de pessoal necessárias para isso. A Lei 9.394/96 conceitua a educação especial como a modalidade de educação escolar oferecida, preferencialmente, na rede regular de ensino, para educandos com necessidades educacionais especiais (BRASIL, 1996). O que inclui 0 atendimento de alunos com deficiência, transtornos globais de desenvolvimento e altas habilidades/superdotação (CAIADO; MELETTI, 2011).

A oferta da educação especial, dever constitucional do Estado, tem início na faixa etária de zero a seis anos, durante a Educação Infantil e contempla toda a escolarização, até o Ensino Superior. Para isso, a LDB (Lei 9.394/96) prevê, quando necessário, serviços de apoio especializado, a exemplo dos professores de educação especial e das salas de recursos multifuncionais, na escola regular para atender as especificidades da demanda da educação especial (BRASIL, 1996). Destarte, para efetivação da Educação Especial é necessário o trabalho conjunto dos professores das classes comuns, do
Atendimento Educacional Especializado - AEE e serviços de apoio como fonoaudiologia e fisioterapia, por exemplo.

A Educação Especial é definida na Lei de Diretrizes e Bases da Educação Nacional (Lei 9.394/96) como uma modalidade transversal que perpassa todos os níveis, etapas e modalidades da educação. Assim sendo, os professores que atuam em todos os níveis de ensino precisam contar, na sua formação inicial e continuada, com conteúdo voltado à educação dos alunos com deficiência - transtornos globais de desenvolvimento e altas habilidades e/ou superdotação - para que possam desenvolver uma pedagogia adequada a estes alunos (BRASIL, 1996).

Mendes (2010) salienta que a formação inicial do professor é de grande relevância, pois a inclusão escolar implica em mudanças na organização do trabalho didático para favorecer o processo de escolarização dos alunos. Segundo a autora,

[...] a formação inicial
renovada e a
profissionalização docente
a partir destes enfoques
propiciarão mudanças nas
metodologias de ensinar,
nas formas de organização
das aulas, no
planejamento de
atividades, nas
acomodações curriculares
e nos sistemas de
avaliação [...] (MENDES,
2010, p. 24).

Nesse sentido, Neres e Kassar (2016) apontam a necessidade urgente de mudanças nas práticas escolares, tendo em vista o atendimento das necessidades educacionais dos alunos com deficiência. Segundo as autoras, essas mudanças implicam em um novo projeto de escola:

[...] fica evidente que há de empreender mudanças nas práticas escolares de tal forma que estas possam de fato atender as necessidades dos alunos com deficiência. Um caminho que se descortina é a necessidade de revisão na forma de conceber o processo de ensino e aprendizagem, considerando a presença 
desses alunos, público alvo da educação especial, que estão frequentando as escolas. Para tal empreitada é preciso se pensar em outro projeto de escola, que de fato possa atender a todos, entre estes, os alunos com deficiência

(NERES; KASSAR, 2016, p. 49).

Portanto, faz-se necessária uma escola que atenda todos os alunos independente de suas necessidades educacionais especiais e que promova um projeto educacional inclusivo. Nessa mesma direção devem caminhar as escolas do campo que se dedicam ao atendimento dos estudantes das populações rurais como agricultores familiares, extrativistas, pescadores artesanais, ribeirinhos, assentados e acampados da Reforma Agrária, quilombolas, indígenas e outros tantos, que vivem na e da terra.

\begin{abstract}
A educação do campo, tratada como educação rural na legislação brasileira, tem um significado que incorpora os espaços da floresta, da pecuária, das minas e da agricultura, mas os ultrapassa ao acolher em si os espaços pesqueiros, caiçaras, ribeirinhos e extrativistas. O campo, nesse sentido, mais do que um perímetro nãourbano, é um campo de possibilidades que dinamizam a ligação dos seres humanos com a própria produção das condições da existência social e com as realizações da sociedade humana (BRASIL, 2012, p. 7-8).
\end{abstract}

Assim, ao pensarmos na educação do campo temos que ter clareza que ela ocorre no território rural, espaço de produção, de vida e de lutas das populações que o habitam. Cabe, portanto, às escolas rurais promover um projeto educacional que consiga valorizar a riqueza sociocultural das populações do campo em diálogo estreito com os conhecimentos historicamente construídos pela humanidade, incluindo todos os educandos sem distinção, inclusive aqueles com necessidades educacionais especiais.

Caiado e Meletti (2011) alertam que a interface entre a educação especial e a educação do campo é desafiadora, uma vez que ambas foram consideradas, recentemente, um direito social e são áreas marcadas pelo histórico descaso nas políticas públicas. Podemos afirmar que esta discussão é recente, enquanto direito social, uma vez que os principais dispositivos legais que tratam da interface educação especial e educação do campo datam da primeira década dos anos 2000.

A necessidade de interface entre a educação especial e a educação do campo aparece em dispositivos legais, como as Diretrizes Operacionais para a Educação Básica nas Escolas do Campo, na Resolução no 2, de 28 de abril de 2008, que complementa a primeira, na Política Nacional de Educação Especial na Perspectiva da Educação Inclusiva; no documento final da Conferência Nacional da Educação, no texto do Plano Nacional de Educação (CAIADO; MELETTI, 2011).

$\mathrm{O}$ atendimento educacional especializado (Resolução no 2, de 28 de abril de 2008), que estabelece diretrizes complementares, normas e princípios para o desenvolvimento de políticas públicas de atendimento da Educação Básica do Campo, prevê que:

Os sistemas de ensino
adotarão providências
para que as crianças e os
jovens portadores de
necessidades especiais,
objeto da modalidade de
Educação
residentes no campo,
também tenham acesso à
Educaçãoral,
preferentementer Básica,
escolas comuns da rede de
ensino regular (BRASIL,
2012, p. 54).

Portanto, a legislação vigente garante o atendimento educacional especializado dos alunos com deficiência que vivem no campo. Entendemos que esse atendimento deve ocorrer nas escolas do campo; entretanto, dado o histórico de fechamento de escolas no campo e o processo de nucleação de escolas, que promove o encerramento de pequenas escolas e obriga os alunos a se deslocarem para escolas maiores, que na maioria dos casos estão mais distantes, 
propicia que vivenciemos cotidianamente o transporte massivo de alunos do meio rural para as escolas urbanas.

Os estudantes com deficiência não escapam a essa realidade, vejamos o caso dos alunos com deficiência auditiva. A partir dos Microdados do Censo Escolar, Caiado e Meletti (2011) mostraram que, em 2010, cerca de 5.000 alunos com deficiência auditiva residiam no campo (em território brasileiro). Destes, aproximadamente 2.400 eram atendidos em escolas urbanas. 0 atendimento aos alunos, nas escolas urbanas, leva-nos a pensar nas condições de deslocamento e transporte, que como sabemos $^{1}$, afeta a maior parte dos alunos com deficiência e sem deficiência, que residem no meio rural e, cotidianamente, enfrentam longas horas no transporte escolar, muitas vezes, em condições precárias de conservação, nas estradas de chão, que caracterizam o rural brasileiro.

Caido e Meletti (2011, p. 102) salientam que,

[...] a impossibilidade de
participação social que as
pessoas com deficiência
enfrentam não se justifica
pela deficiência em si. Essa
impossibilidade, traduzida
muitas vezes por
incapacidade, é resultado
das barreiras sociais a que
diuturnamente estão
expostas. Esse quadro se
torna ainda mais
complexo ao pensarmos
nas precárias condições de
vida que enfrentam os que
vivem no campo. Na
ausência de políticas
públicas para a população
do campo, seja em
educação, saúde,
transporte, moradia e
trabalho, revela-se o
impedimento de pessoas
com deficiência viverem
com dignidade re
participarem da vida
social.

Além disto, Caiado e Meletti (2011) asseveram que o silêncio da produção científica sobre a interface da Educação Especial na

\footnotetext{
${ }^{1}$ Questão trabalhada em Basso (2013).
}

educação do campo impõe um grande desafio aos pesquisadores.

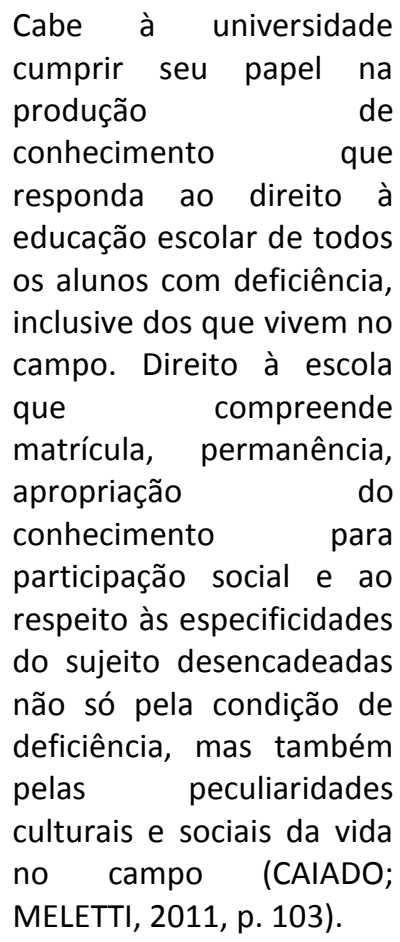

Este silêncio revela, não apenas, a necessidade de pesquisas na área, como o histórico apagamento da demanda por Educação Especial, uma vez que muitos dos alunos com deficiência não chegam a ser matriculados em instituições educacionais. Parte deles, cujas famílias possuem condições materiais, recebem formação em suas moradias, outros nunca terão acesso ao conjunto de conhecimentos historicamente produzidos pela humanidade.

É nesse sentido que se torna fundamental a efetivação da Educação Especial em escolas urbanas e rurais. Uma das ferramentas para que isso ocorra é o ensino de Libras nos cursos de formação de professores (inicial e continuada), bem como o estímulo à realização de debates, em sala, sobre o assunto, ao oferecimento de cursos de extensão universitária e à realização de pesquisas, em nível de Graduação e PósGraduação, que colaborem com o aprofundamento da produção científica sobre a temática.

\section{A LÍNGUA BRASILEIRA DE SINAIS - LIBRAS NA FORMAÇÃO DE PROFESSORES}

A pessoa surda é aquela que, por ter perda auditiva parcial ou total, compreende e interage com o mundo por meio de experiências visuais, manifestando sua cultura, principalmente, pelo uso da Língua Brasileira de Sinais - Libras (BRASIL, 2005). Assim, a Libras é 
considerada a primeira língua com que o deficiente auditivo tem contato. É por meio dela que se ensina o português, como segunda língua. $\mathrm{Na}$ língua de sinais, o movimento das mãos corresponde a uma palavra, a uma ideia ou, às vezes, a uma frase. As ordens dos movimentos não correspondem, fielmente, à língua falada, ou seja, sua estrutura não é a mesma da Língua Portuguesa (ROSSI, 2010).

Rossi (2010) explica que a perda auditiva faz com que o indivíduo tenha maior acesso ao canal visual, o que torna a língua de sinais, biologicamente, natural para eles. Ao ter acesso ao bilinguismo, o surdo amplia seu leque de recursos linguísticos, atendendo suas necessidades, favorecendo o acesso a qualquer tipo de conceito ou conhecimento. Desse modo, o acesso aos conhecimentos historicamente construídos, no caso dos alunos surdos, passa pelo domínio da Língua Brasileira de Sinais.

Dada a importância da Libras para os alunos surdos, o Decreto 5.626 de 05 de dezembro de 2005 lhes garantiu o direito à formação em Libras e em Língua Portuguesa, de preferência na modalidade escrita e o acesso às duas línguas de modo simultâneo no ambiente escolar. Esse mesmo decreto inseriu a Libras como disciplina curricular obrigatória, nos cursos de formação de professores para o exercício do magistério, em nível médio e superior, e nos cursos de Fonoaudiologia, ofertados por instituições públicas e privadas, dos sistemas federal e estadual de ensino, do Distrito Federal e dos Municípios (BRASIL, 2005).

Renata Aparecida Rossi (2010) destaca que a inserção da Libras como disciplina, nos cursos de formação de professores, é uma conquista para a comunidade surda, na direção de uma educação bilíngue (Português/Libras). Rossi (2010) prossegue salientando que, dado o papel fundamental da linguagem no processo de interação e nos processos cognitivos de toda criança, a criança surda encontra-se prejudicada pelas oportunidades insuficientes oferecidas pela sociedade e pelo sistema educacional, pelo fato do professor e do aluno não compartilharem a mesma língua, o que torna imprescindível a Libras na formação docente.

$\mathrm{Na}$ perspectiva inclusiva da educação de pessoas com surdez, o bilinguismo que se propõe é aquele que destaca a liberdade de o aluno se expressar em uma ou em outra língua e de participar de um ambiente escolar que desafie seu pensamento e exercite sua capacidade perceptivo-cognitiva, suas habilidades para atuar em interagir em um mundo social que é de todos, considerando

0 contraditório, o ambíguo, as diferenças entre as pessoas (ALVEZ et al., 2010, p. 9).

Portanto, é essencial que todos os professores aprendam a Língua Brasileira de Sinais - Libras e sua importância na escolarização de alunos surdos para que estes tenham liberdade de se expressar do modo que mais favoreça seu desenvolvimento cognitivo. Nesse sentido, Calixto (2018, p. 105) destaca que:

[...] os alunos da disciplina
de Libras, nos cursos de
Licenciatura precisam
conhecer esses aspectos
da constituição do sujeito
surdo como um sujeito
que apresenta uma
diferença cultural, com
uma língua diferente,
como experiência
diferentes e com
capacidade e habilidade
de aprendizado e de
participação no ambiente
que está, e mais
especificamente no
ambiente escolar, onde
esses futuros docentes
terão contato mais direto
com estes sujeitos.

Desta forma, cabe à disciplina de Libras formar professores capazes de compreender o indivíduo com deficiência auditiva enquanto sujeito de direitos e que possui uma forma de comunicação e cultura próprias. Entretanto, Rossi (2010) destaca que o aluno com deficiência auditiva é prejudicado no processo de inclusão, dado o despreparo dos professores das salas regulares e dos professores das salas de recursos multifuncionais.

Com vistas a importância da Libras na escolarização bilíngue dos alunos com deficiência auditiva, e o denunciado despreparo de professores para esse processo, é que 
discutiremos a inclusão da Libras nos cursos de formação docente para o campo. Iniciando pela compreensão das iniciativas de formação de professores para o campo e o contexto que as possibilitou.

\section{A FORMAÇÃO DE PROFESSORES PARA O CAMPO NO PROGRAMA NACIONAL DE EDUCAÇÃO NA REFORMA AGRÁRIA- PRONERA}

Dentre as possibilidades de cursos de formação de professores para as escolas do campo estão as que ocorrem no âmbito do Programa Nacional de Educação na Reforma Agrária - Pronera que,

[...] é uma política pública do governo federal, específica para a educação formal de jovens e adultos assentados da Reforma Agrária e do crédito fundiário e para a formação de educadores que trabalham nas escolas dos assentamentos ou do seu entorno e atendam a população assentada. 0 programa foi criado em 16 de abril de 1998, por portaria do então Ministério Extraordinário da Política Fundiária (MEPF), num contexto de ascenso da luta pela Reforma Agrária que aliava as condições de forte organização e mobilização dos Sem Terra por todo o território nacional à sensibilidade da sociedade brasileira em torno da causa, mobilizada após os massacres de Corumbiara, em Rondônia, em 1995, e de Eldorado dos Carajás, no Pará, em 1996 (SANTOS, 2012, p. 632).

Naquele contexto de luta pela Reforma Agrária, os movimentos sociais do campo colocaram em pauta várias questões, dentre elas, a insuficiência de escolas e professores na área rural. $O$ que restringe o acesso das populações do campo aos anos iniciais do Ensino Fundamental, perpetuando a negação histórica do direito dessa população aos níveis mais elevados de escolarização (SANTOS, 2012).
O Censo da Reforma Agrária, realizado em 1997, evidenciou que os índices de analfabetismo, presentes nos assentamentos da Reforma Agrária, são superiores aos da população rural. Aquele baixo índice de escolaridade se devia à ausência do poder público municipal e estadual, nas áreas de assentamento da Reforma Agrária. Em 2005, a I Pesquisa Nacional de Educação na Reforma Agrária - Pnera, realizada pelo Incra/Pronera, em conjunto com o Instituto Nacional de Estudos e Pesquisas Educacionais (Inep), do Ministério da Educação (MEC), evidenciou que $23 \%$ da população assentada declarou-se analfabeta e que, em sua maioria, só tinham acesso aos anos iniciais do Ensino Fundamental. De acordo com Santos (2012, p. 632):

Em razão destes resultados, o Pronera, que até então executava majoritariamente projetos de alfabetização e escolarização em séries iniciais, passou a incentivar projetos de ensino fundamental completo e nível médio. Com o desenvolvimento destes projetos, a consequente conclusão deste nível de ensino e a necessidade de formação de professores para as escolas conquistadas para os PAs [Projetos de Assentamento], os próprios movimentos sociais passaram a demandar projetos de cursos superiores, inicialmente restritos à área de Pedagogia e licenciaturas, posteriormente ampliados para outras áreas, como as de Ciências Agrárias.

Segundo o Manual de Operações do Pronera,

Os projetos em nível superior destinam-se a garantir a formação profissional para qualificar as ações dos sujeitos e disponibilizar, em cada área de Reforma Agrária, recursos humanos 


$$
\begin{aligned}
& \text { capacitados que } \\
& \text { contribuam para } 0 \\
& \text { desenvolvimento } \\
& \text { socialmente justo e } \\
& \text { ecologicamente } \\
& \text { sustentável (PRONERA, } \\
& \text { 2016, p. 57). }
\end{aligned}
$$

Portanto, os cursos de nível superior ofertados pelo Pronera visam a formação de profissionais alinhados a uma perspectiva de desenvolvimento social mais justa e sustentável. O que, segundo Camacho (2015), caracteriza a tentativa de construir uma democracia para além do modelo da economia liberal.

O programa se destina ao atendimento da população jovem e adulta das famílias beneficiárias das Áreas de Reforma Agrária criadas ou reconhecidas pelo Instituto Nacional de Colonização e Reforma Agrária - INCRA e do Programa Nacional de Crédito Fundiário - PNCF. $O$ ingresso nos cursos de nível superior se dá por meio de processo seletivo realizado pela e deve conter instrumentos que abarquem as temáticas: questão agrária, fundiária e agrícola brasileira; Educação do Campo; realidade local e estratégias de desenvolvimento sustentável regional (PRONERA, 2016).

Um dos projetos de nível superior do Pronera é o Curso Especial de Licenciatura em Pedagogia da Terra, que tem como objetivo formar pedagogos com ênfase no trabalho nas escolas em áreas de assentamento da reforma agrária. Além das iniciativas do Pronera, é fundamental citarmos o Programa de Apoio à Formação Superior em Licenciatura em Educação do Campo - PROCAMPO, empreendido pelo Ministério da Educação MEC, e que desde 2007 tem promovido a formação docente por meio da Licenciaturas em Educação do Campo. O processo iniciou com a implementação de quatro experiências-piloto em Universidades Federais de Minas Gerais, Brasília, Sergipe e Bahia. Política que resultou de reivindicações de trabalhadores rurais (MOLINA, 2017).

A partir das experiênciaspiloto, em 2008 e 2009, o MEC lançou editais para que mais universidades também pudessem ofertar a Licenciatura, porém como projeto especial de turmas únicas. Em 2012, a partir da pressão dos movimentos sociais do

\begin{abstract}
campo, foram conquistados 42 cursos permanentes dessa nova graduação em todas as regiões do país. Objetivando garantir a implementação dos cursos, o Ministério da Educação disponibilizou 600 vagas de concurso público de docentes da educação superior e 126 vagas de técnicos como suporte para esse processo (MOLINA, 2017, p. 589).
\end{abstract}

Deste modo, as Licenciaturas em Educação do Campo se firmaram em quarenta e duas Universidades Federais brasileiras e representam uma vitória na luta das populações rurais pela educação do campo em nível superior, uma vez que, dentre outros fatores, foi garantida a contratação permanente de profissionais para o atendimento desta demanda. Esses cursos visam a formação de professores que atuarão nos anos finais do ensino fundamental e ensino médio em escolas rurais em diferentes áreas do saber (MOLINA, 2017).

Podemos afirmar, então, que os cursos de formação docente para o campo, tanto aqueles oferecidos pelo Pronera tanto as Licenciaturas em Educação do Campo, são resultantes das lutas das populações do campo pelo direito à educação. Nesse sentido, na sessão seguinte nos dedicaremos ao caso de um Curso Especial de Licenciatura em Pedagogia da Terra, destacando o modo como a disciplina de Libras aparece em seu Projeto Político Pedagógico e seus impactos na formação dos professores que atuarão nas escolas do campo.

\section{A LÍNGUA BRASILEIRA DE SINAIS - LIBRAS E A FORMAÇÃO DE PROFESSORES PARA O CAMPO: O CASO DO CURSO DE PEDAGOGIA DA TERRA}

A partir de todo o exposto, analisaremos o caso do Curso Especial de Licenciatura em Pedagogia da Terra, oferecido pela Universidade Federal de São Carlos - UFSCar, que formou duas turmas, uma no ano de 2011 e outra em 2018. Para isso, embasamo-nos em revisão bibliográfica, na análise documental do Projeto Político Pedagógico mais recente do curso, elaborado no ano de 2014, e em um estudo de caso de natureza qualiquantitativa a partir de 
indicadores e depoimentos levantados por meio da aplicação de questionário com uma amostra dos egressos das duas turmas do curso.

O Projeto Político Pedagógico do Curso Especial de Licenciatura em Pedagogia da Terra foi elaborado por docentes e técnicos da UFSCar em parceria com representantes dos setores de educação da Organização de Mulheres Assentadas e Quilombolas do Estado de São Paulo - OMAQUESP; Associação Estadual de Cooperação Agrícola - AESCA/SP, associação composta por trabalhadores rurais assentados do Movimento dos Trabalhadores Rurais Sem Terra - MST e o Instituto Nacional de Colonização e Reforma Agrária - INCRA (UNIVERSIDADE FEDERAL DE SÃO CARLOS, 2014, p. 7). Parceria necessária para a aproximação do curso com a demanda que os egressos do curso atendem, mas que não ocorre de modo passivo.

$$
\begin{aligned}
& \text { A relação entre a } \\
& \text { universidade e os } \\
& \text { movimentos sociais nem } \\
& \text { sempre se dá ou se deu da } \\
& \text { forma mais tranquila, } \\
& \text { sobretudo devido à } \\
& \text { autonomia e aos objetivos } \\
& \text { de ambos e, por vezes, à } \\
& \text { incompreensão do que } \\
& \text { seria esta autonomia. } \\
& \text { Além disso, não é raro } \\
& \text { setores de alguns } \\
& \text { movimentos sociais } \\
& \text { enxergarem na } \\
& \text { universidade um braço do } \\
& \text { próprio Estado burguês } \\
& \text { que os oprime, expropria e } \\
& \text { exclui da participação em } \\
& \text { seu seio [...] Apesar desta } \\
& \text { relação ser muito boa em } \\
& \text { alguns momentos } \mathrm{e} \\
& \text { difíceis em outros, os } \\
& \text { movimentos sociais têm } \\
& \text { contribuído bastante no } \\
& \text { sentido de ajudar a tornar } \\
& \text { pública a universidade, } \\
& \text { quer pelo seu acesso, quer } \\
& \text { por suas práticas } \\
& \text { pedagógicas que são } \\
& \text { levadas para as } \\
& \text { comunidades pela turma } \\
& \text { [...] (UNIVERSIDADE } \\
& \text { FEDERAL DE SÃO CARLOS, } \\
& \text { 2014, p. 50). }
\end{aligned}
$$

Portanto, pensar a formação de professores para o campo requer 0 reconhecimento da importância dos movimentos sociais do campo ante o enfrentamento das contradições que caracterizam as sociedades capitalistas como um todo e no processo de abertura das universidades públicas brasileiras às populações rurais, dentre elas os sujeitos com deficiência.

Foi buscando aprofundar a
formação do trabalhador
do campo e sobretudo a
formação dos educadores
que aí trabalham que se
formou a primeira turma
de Pedagogia da Terra da
UFSCar. A turma
denominada "Helenira
Resende" foi formada com
vistas a discutir a
educação do homem do
campo sob uma
perspectiva diferente
daquela que tem sido
praxe, ou seja, a
perspectiva de uma
educação específica para
essa parcela da população
(UNIVERSIDADE FEDERAL
DE SÃO CARLOS, 2014, p.
50-51).

Nessa perspectiva, em 2011, a primeira turma do curso formou quarenta e um pedagogos. Em 2014, a segunda turma ingressou com o intuito de "formar os participantes para atuarem com autonomia junto a seus pares na concepção, elaboração e implementação de projetos de ensino-aprendizagem tanto no âmbito escolar quanto no âmbito comunitário mais amplo" (UNIVERSIDADE FEDERAL DE SÃO CARLOS, 2014, p. 55). Daquela segunda oferta, dezessete educandos concluíram o curso, em 2018. Portanto, foram graduados cinquenta e oito profissionais voltados ao trabalho docente, com ênfase na atuação em escolas em áreas de assentamento da reforma agrária.

Para tanto, o curso se estruturou em três grandes eixos: docência, gestão democrática e pesquisa na perspectiva educativa. A pesquisa foi o eixo articulador da matriz curricular. Assim:

A finalidade desse eixo é formar o aluno inquiridor, capaz de propor questões e não só de dar respostas às tarefas solicitadas; capaz de levantar hipóteses explicativas a situações educativas e de propor alternativas de 
ação pedagógica com vista à inclusão pedagógica e social, favorecendo a aprendizagem de todos os seus alunos (UNIVERSIDADE FEDERAL DE SÃO CARLOS, 2014, p. 64).

Esperava-se que os egressos do Curso de Pedagogia da Terra fossem capazes de buscar alternativas teóricas e práticas para a efetivação da inclusão escolar e social de todos os alunos, sem distinção. Quanto ao atendimento dos alunos com deficiência, estavam entre as áreas de competências e seus respectivos conhecimentos e habilidades a "capacidade para identificar a problemática pedagógica envolvida na educação das pessoas com necessidades educativas especiais" (UNIVERSIDADE FEDERAL DE SÃO CARLOS, 2014, p. 63).

Para desenvolver essas competências, conhecimentos e habilidades, foram oferecidas duas disciplinas específicas: Fundamentos de Educação Especial e Ensino de Libras. A disciplina de Fundamentos de Educação Especial "Estuda a história da educação especial no Brasil. Conhece trabalhos pedagógicos significativos na área. Estuda as possibilidades de interface da educação especial no campo" (UNIVERSIDADE FEDERAL DE SÃO CARLOS, 2014, p. 138). Tendo como objetivo "levar o educando a compreender os problemas da educação especial no Brasil" (UNIVERSIDADE FEDERAL DE SÃO CARLOS, 2014, p. 138). Portanto, visou oferecer conhecimentos históricos e práticos que permitissem, além da capacidade de cooperar com o atendimento educacional especializado, dinamizar sua interface com a educação do campo.

Já a disciplina Ensino de Libras, "estuda a língua brasileira de sinais, possibilitando a atuação do educando junto aos alunos com deficiências" (UNIVERSIDADE FEDERAL DE SÃO CARLOS, 2014, p. 140). Tendo como objetivos "Levar o educando a conhecer e dominar a língua brasileira de Sinais" (UNIVERSIDADE FEDERAL DE SÃO CARLOS, 2014, p. 14).

Quanto à organização do curso e forma de oferecimento de todas as suas disciplinas, é importante saber que o Curso Especial de Licenciatura em Pedagogia da Terra da UFSCar, assim como outros cursos de Ensino Superior oferecidos às populações do campo, ocorre em regime de alternância em que se alternam os tempos educativos na Instituição de Ensino Superior e nas comunidades onde os sujeitos vivem e trabalham. Silva (2010, p. 184) esclarece que,

[...] a alternância é
considerada com sendo
estratégia para abertura
do mundo escolar a
realidade de vida dos
jovens; para flexibilização
da organização do
calendário escolar e
adequação a vida no meio
rural; aplicação do
conhecimento escolar na
propriedade dos jovens;
realização de estágio de
vivência; entre outros.

No caso estudado, o tempo escola varia entre vinte e cinco e quarenta e cinco dias em que os estudantes permanecem na Universidade, tendo aulas de segunda a sábado, em regime integral, nessa organização parte das disciplinas são ofertadas de modo condensado. Cada etapa é composta por um tempo escola, o curso todo ocorre em oito etapas (quatro anos). Nesse período o curso também garante alojamento aos estudantes e alimentação que durante a semana é oferecida no Restaurante Universitário e aos finais de semana no próprio alojamento. Ações que garantem a permanência dos alunos durante o tempo escola.

Já o tempo comunidade, por se tratar de curso de formação docente, se materializa por meio da realização de estágios curriculares supervisionados e realização de atividades de pesquisa em escolas nas áreas rurais onde os alunos moram e trabalham. Ambas as atividades são realizadas sob a supervisão de um professor monitor que periodicamente vai até as comunidades. Este tempo se alterna aos tempos escola e visa a aplicação daquilo que foi apreendido nas diferentes disciplinas que compõem a grade curricular do curso. Deste modo, segundo Silva (2010), a formação por alternância constitui uma dinâmica contínua entre teoria e prática.

Nesse contexto, para compreendermos melhor a inclusão da Libras como componente curricular obrigatório nos cursos de formação docente para professores do campo, realizamos um estudo de caso de cunho qualiquantitativo a partir do Curso Especial de Licenciatura em Pedagogia da Terra oferecido na UFSCar. O 
estudo de caso permite a abordagem de um tema específico ou particular da ciência, abordando vários aspectos do objeto estudado (LAKATOS; MARCONI, 2003).

Optamos pela coleta de dados estatísticos e de depoimentos por meio de um questionário misto, composto por questões fechadas (múltipla escolha) e abertas (discursivas), dado o número de sujeitos convidados a participar da pesquisa, visto que o questionário permite observação direta e extensiva (LAKATOS; MARCONI, 2003). Procedimento metodológico que se justifica, uma vez que "na pesquisa em ciências sociais, frequentemente são utilizados resultados e dados expressos em números. Porém, se interpretados e contextualizados à luz da dinâmica social mais ampla, a análise torna-se qualitativa" (GAMBOA, 2009, p. 106).

Deste modo, este foi o percurso metodológico adotado: os cinquenta e oito egressos das turmas formadas nos anos de 2011 e 2018 foram convidados a participar da pesquisa em dezembro de 2019 e o fizeram naquele mesmo mês e em janeiro de 2020. O instrumento de pesquisa (questionário) foi enviado por meio de um link para o Google Formulários. O grande número de possíveis participantes foi preponderante na opção pela aplicação de questionário, que permite a coleta extensiva de dados.

Dos cinquenta e oito sujeitos convidados, sete responderam ao questionário, 0 que representa uma amostra de cerca de $12 \%$ daqueles que concluíram o curso nas duas turmas. Todos os participantes da pesquisa concordaram com o Termo de Consentimento Livre e Esclarecido, que lhes garantiu a preservação da identidade no trato e exposição dos resultados e o direito à desistência da participação na pesquisa a qualquer momento. É fundamental destacarmos que todos os participantes da pesquisa são maiores de idade.

A partir disto, iniciamos questionando se os egressos estavam exercendo a docência naquele momento, obtivemos o seguinte resultado:

Tabela 1. Exercício da Docência

\begin{tabular}{ll}
\hline Sim & 4 \\
\hline Não & 3 \\
\hline
\end{tabular}

Fonte: As autoras.

Tabela 2. Tipo de escola em que trabalham

\begin{tabular}{cl}
\hline Escolas de Assentamentos & 2 \\
\hline Escolas Urbanas & 2 \\
\hline
\end{tabular}

Fonte: As autoras.

Portanto, cerca de $57 \%$ da amostra dos egressos do Curso de Pedagogia da Terra, participantes da pesquisa, estavam exercendo função docente em janeiro de 2020. Questionamos em seguida em que tipo de escola estavam lecionando, estas foram as respostas:

Apenas dois dos participantes da pesquisa estavam trabalhando em escolas localizadas em Assentamentos da Reforma Agrária naquele momento, outros dois o faziam em escolas urbanas.

Para compreendermos as condições de trabalho desses docentes, questionamos acerca do regime de trabalho:

Tabela 3. Regime de contratação docente

\begin{tabular}{cl}
\hline Concursado Rede Pública & 1 \\
\hline Contratado Rede Pública & 2 \\
\hline Vincula à Movimento Social & 1 \\
\hline
\end{tabular}

Fonte: As autoras. 
Os indicadores nos mostram que dentre os questionados, apenas um apresentava estabilidade empregatícia por meio de concurso na Rede Pública de Ensino, enquanto outros dois também estavam na Rede Pública, porém em contrato temporário de trabalho. Um outro exercia docência vinculado a um movimento social.

Visando identificar a atuação destes egressos do Curso Especial de Licenciatura em Pedagogia da Terra junto a alunos com deficiência auditiva e a efetividade da formação voltada à Educação Especial e à Libras recebida no curso, elaboramos uma série de questões, a primeira delas foi: se já haviam atendido algum aluno com deficiência auditiva em ambiente escolar. Como estas questões não estavam atreladas ao vínculo empregatício dos docentes, toda a amostra foi analisada, assim coletamos os seguintes indicadores:

Tabela 4. Atendimento de alunos com deficiência auditiva

\begin{tabular}{ll}
\hline Sim & 1 \\
\hline Não & 6 \\
\hline
\end{tabular}

Fonte: As autoras.

Como resposta, obtivemos a informação de que apenas um dos professores já havia recebido alunos com deficiência auditiva ao longo de sua trajetória profissional. Quanto ao uso da
Libras no contexto escolar, como mostra a tabela 5 , apenas dois dos sete docentes já haviam se comunicado em Libras na escola.

Tabela 5. Utilização da Libras no contexto escolar

\begin{tabular}{ll}
\hline Sim & 2 \\
\hline Não & 5 \\
\hline
\end{tabular}

Fonte: As autoras.

Em seguida, questionamos se os participantes da pesquisa já tinham conhecimento da existência da Libras antes de cursar as disciplinas ofertadas no curso de
Licenciatura em Pedagogia da Terra. Estes foram os resultados:

Tabela 6. Conhecimento prévio da existência da Libras

\begin{tabular}{ll}
\hline Sim & 6 \\
\hline Não & 1 \\
\hline
\end{tabular}

Fonte: As autoras.

Portanto, quase $86 \%$ dos questionados já tinham conhecimento da existência da Língua Brasileira de Sinais - Libras, o que nos dá indícios de que embora não seja de domínio geral, essa língua, que é a primeira para a formação das pessoas surdas, é reconhecida por parte da população brasileira. Observa-se também que as duas turmas da UFSCar vivenciaram experiências diferentes com a disciplina "Ensino de Libras". Uma delas foi ofertada por professor ouvinte, ou seja, sem deficiência auditiva (frequentada por quatro dos participantes da pesquisa), enquanto a outra foi ministrada por docente surdo, que se comunicava, predominantemente, em Libras (frequentada por três egressos).

Questionamos os participantes sobre a relação teoria e prática na disciplina "Ensino de Libras", esses foram os indicadores: 
Tabela 7. Relação teoria e prática na disciplina "Ensino de Libras"

\begin{tabular}{cl}
\hline Predominantemente teórica & 0 \\
\hline Predominantemente prática & 0 \\
\hline Equilibrada entre teoria e prática & 7
\end{tabular}

Fonte: As autoras.

Os egressos das duas ofertas sinalizaram, em unanimidade, que a disciplina "Ensino de Libras" foi equilibrada em teoria e prática. $\mathrm{Na}$ sequência os participantes foram questionados quanto ao entendimento das explicações e demonstrações práticas do professor de Libras, os resultados foram estes:

Tabela 8. Compreensão da disciplina "Ensino de Libras"

\begin{tabular}{cl}
\hline Compreendia bem & 6 \\
\hline Compreendia com certa dificuldade & 0 \\
\hline Muita dificuldade de compreensão & 1 \\
\hline
\end{tabular}

Fonte: As autoras.

Percebe-se que seis dos sete sujeitos de pesquisa afirmaram que compreendiam bem 0 que o professor explicava e demonstrava, enquanto um deles afirmou ter tido muita dificuldade de compreensão nas aulas. Complementando essa discussão os participantes avaliaram a disciplina "Ensino de Libras" quanto ao seu potencial de formação teórico e prático, este último traduzido na capacidade de se comunicar em Libras; os resultados foram seguintes:

Tabela 9. Avaliação da disciplina "Ensino de Libras"

\begin{tabular}{cl}
\hline Suficiente em termos teóricos e práticos & 0 \\
\hline Suficiente em termos teóricos & 6 \\
\hline Insuficiente em termos teóricos e práticos & 1 \\
\hline
\end{tabular}

Fonte: As autoras.

Assim, cerca de $86 \%$ dos participantes asseguraram que a disciplina foi suficiente em termos teóricos, mas não os capacitou para a comunicação fluente em Libras e um outro afirmou que as aulas não foram suficientes, tanto em termos teóricos, quanto práticos. Mesmo todos eles tendo avaliado anteriormente que a disciplina foi equilibrada na relação entre teoria e prática. À vista disto, Louzada et al. (2017, p. 868) afirmam que:

é fato, que não se pode atribuir à oferta dessa disciplina a possibilidade de domínio da língua, dado o limite de carga horária, porém, deve-se destacar que a partir deste decreto as diferenças

$\begin{array}{lr}\text { linguísticas } & \text { e } \\ \text { socioculturais } & \text { das } \\ \text { comunidades } & \text { surdas } \\ \text { passaram a receber } & \text { rlguma atenção nos cursos } \\ \text { de formação de } & \\ \text { professores. }\end{array}$

Ou seja, mesmo com as limitações em relação à disciplina de Libras, o Decreto 5.626/2005 colaborou com a colocação da escolarização dos surdos em pauta nos cursos de formação docente. Nessa perspectiva, no que tange ao uso da Libras durante as aulas, obtivemos os seguintes indicadores: 
Tabela 10. Uso da Libras durante as aulas

\begin{tabular}{cl}
\hline Conseguia se comunicar em Libras & 3 \\
\hline Certa dificuldade em se comunicar em Libras & 3 \\
\hline Não conseguia se comunicar em Libras & 1 \\
\hline
\end{tabular}

Fonte: As autoras.

Os indicadores evidenciam que apenas cerca de $43 \%$ dos egressos participantes da pesquisa não apresentaram dificuldades em se comunicar em Libras durantes as aulas da licenciatura. Para compreender essa situação, questionamos quais seriam as principais dificuldades enfrentadas na disciplina "Ensino de Libras". Os resultados foram os seguintes:

Tabela 11. Dificuldades enfrentadas na disciplina em Libras

\begin{tabular}{cl}
\hline Compreender o professor e a Libras & 1 \\
\hline Se comunicar em Libras & 5 \\
\hline Outras & 1 \\
\hline
\end{tabular}

Fonte: As autoras.

Os indicadores apontam para a dificuldade dos professores em formação se apropriarem da Língua Brasileira de Sinais Libras, fato que se evidenciou em boa parte dos resultados aqui apresentados. Acrescido a isto, ao assinalar a opção "outras" um dos participantes mencionou o fato da disciplina ter sido ofertada de modo condensado, ao longo de uma semana, dada a organização do curso por alternância.

Questionamos, também, quanto à realização de cursos de capacitação em Libras, após a conclusão da Licenciatura, obtivemos os seguintes indicadores:

Tabela 12. Realização de formação continuada em Libras

\begin{tabular}{ll}
\hline Sim & 2 \\
\hline Não & 5 \\
\hline
\end{tabular}

Fonte: As autoras.

Dos dois egressos, que realizaram formação continuada em Libras, um deles o fez em nível de especialização e outro em nível básico, em curso pago, na própria instituição onde cursou a Pedagogia da Terra.

Assim, os indicadores apresentados evidenciaram que, na amostra analisada, mesmo a maioria dos licenciados tendo conhecimento anterior da existência da Libras e ter alegado conseguir compreender as explicações e as demonstrações do professor da disciplina "Ensino de Libras", a maior parte deles não se considerou capacitada para se comunicar com o uso dos sinais em seu cotidiano de trabalho, relatando dificuldades na apropriação da Língua Brasileira de Sinais.

Feitas as questões fechadas cujos resultados expusemos, foram propostas questões abertas (dissertativas). $\mathrm{Na}$ primeira delas, pedimos que os participantes sugerissem melhorias na disciplina "Ensino de Libras", sobre a qual cinco dos sete egressos mencionaram a ampliação da carga horária e maior número de aulas (tendo em vista que a disciplina teve trinta horas-aula); um deles asseverou ainda que seria interessante a disciplina ser ministrada no início do curso (primeiro período), o que possibilitaria colocar a Libras em prática em outros momentos e espaços formativos, como por exemplo, no estágio curricular obrigatório. Novamente, a oferta da disciplina de forma condensada foi apontada como um obstáculo à aprendizagem da Libras.

Dentre as sugestões, uma delas merece destaque, a de que a Libras faça parte da cultura cotidiana do curso, visto que é essencial destacarmos que o preparo para o atendimento educacional especializado na formação de 
professores extrapola o limite das disciplinas específicas e deve ser trabalhado de modo transversal ao longo de todo o curso.

Nesse sentido, para além da proficiência em Libras, questionamos os egressos do Curso Especial de Licenciatura em Pedagogia da Terra acerca da importância da Libras no processo de formação docente e no atendimento educacional especializado das pessoas surdas. Quando questionados sobre a importância da Libras na formação docente inicial, os egressos foram unânimes quanto à relevância da Libras no processo de inclusão, na formação do profissional capaz de atender os alunos surdos e que, mesmo não os tornando proficientes em libras ofereceu um "norte" para que busquem outros caminhos e mais qualificação. Nas palavras de um dos egressos:

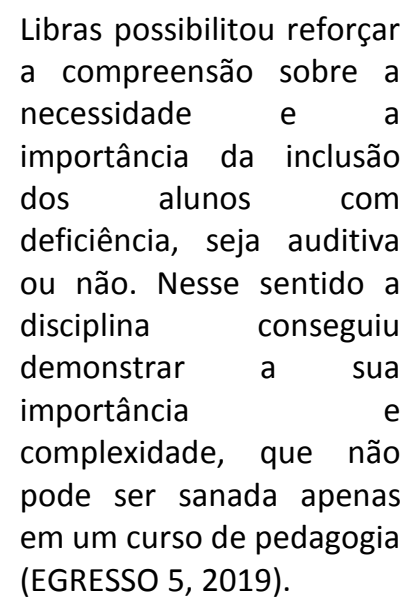

É evidente a limitação temporal de uma disciplina na matriz curricular de um curso de licenciatura, porém ela cumpre seu papel ao sensibilizar os futuros docentes e lhes oferecer os conhecimentos e problematizações que lhes permitam ampliar os conhecimentos e perceber a relevância social da Educação Especial.

Dando seguimento a essa problemática, questionamos os egressos se a disciplina "Ensino de Libras" colaborou para que tivessem outro olhar acerca da deficiência auditiva. Todos os participantes afirmaram terem modificado o modo como percebem as pessoas com surdez. Dentre as respostas, destacamos duas. A primeira delas relata a experiência com o professor surdo: “[...] a troca de lugar é extremamente valiosa. Estamos acostumados com professores falantes e de repente chegou um surdo que nos ensinou sua língua. Nos colocou exatamente no lugar das crianças que vamos encontrar nas salas de aula" (EGRESSO 7, 2020).
Esse relato nos evidencia a importância da formação bilíngue, visto que, a Libras é a primeira língua a que o surdo tem acesso, nesse sentido,

[...] a abordagem
educacional por meio do
bilinguismo visa capacitar
a pessoa com surdez para
a utilização de duas
línguas no cotidiano
escolar e na vida social,
quais sejam: a língua de
sinais e a língua da
comunidade ouvinte.
Estudos têm demonstrado
que esta abordagem
corresponde melhor às
necessidades do aluno
com surdez, em virtude de
respeitar a língua natural e
construir um ambiente
propício para a sua
aprendizagem escolar (ALVES et al., 2010, p. 7-8).

Esse "outro olhar" a que nos referimos, diz respeito, dentre outras coisas, ao reconhecimento da Libras enquanto língua natural e essencial ao processo de escolarização dos alunos com deficiência auditiva e da necessidade de efetivação da inclusão social e escolar. Nessa direção, o Egresso 2 (2019), colaborou com o seguinte relato:

A disciplina de Libras
possibilitou
conhecimento de modo
que nos fizeram refletir
sobre a exclusão e a
inclusão dos sujeitos que
possuem deficiência, a fim
de avançarmos no que diz
respeito ao direito tanto
dos professores ter
formação suficiente que
consiga auxiliar o aluno,
quanto o aluno tenha
conhecimento e que possa
frequentar espaços como
por exemplo a escola, em
que seja acolhido/incluso
atendendo as suas
necessidades.

Parece-nos, a partir da amostra analisada, que a presença da Libras na grade curricular dos cursos de formação de professores supera a perspectiva da instrumentação dos profissionais 
na Língua de Sinais e colabora para que professores tenham consciência dos direitos daqueles que possuem algum tipo de deficiência. Para Louzada et al. (2017, p. 877) "a inserção desta disciplina na formação docente, representa uma conquista recente dos movimentos da militância da área da surdez em favor do reconhecimento desta língua no desenvolvimento cognitivo, linguístico e educacional dos surdos."

Visando compreender melhor este tema, questionamos os egressos do curso sobre a importância da Libras no processo de inclusão dos alunos surdos, dentre os pontos destacados estão: a visibilidade dos sujeitos surdos e/ou com algum tipo de deficiência; a possibilidade de pertencimento e interação social dos surdos; a importância de um trabalho conjunto multidisciplinar para efetivação da inclusão escolar e, nas palavras de um dos egressos, "a importância está em fazer com que a criança consiga aprender sem medo e sem vergonha" (EGRESSO 6, 2020).

Com isso, acreditamos que a Libras é essencial não só para a aquisição dos conhecimentos ditos escolares, mas também para que os surdos se reconheçam enquanto sujeitos de direitos sociais e educacionais. Assim, inquirimos os egressos do curso se - a partir de suas experiências em escolas, movimentos sociais e outros espaços - eles acreditam que os direitos dos alunos surdos têm sido respeitados. É importante destacar que dentre os direitos educacionais dos alunos surdos estão: o atendimento educacional bilíngue em escolas comuns (em Libras e em língua nativa, no caso do Brasil, o português); a presença de um intérprete de Libras em sala de aula; o preparo do professor de sala regular, por meio do domínio da Libras, e outras questões pertinentes à inclusão e ao Atendimento Educacional Especializado - AEE em Libras no contraturno (ALVES et al., 2010).

Sobre essa questão, um dos participantes optou em não emitir opinião por não estar exercendo atividade docente, os demais (seis) foram unânimes em avaliar que os direitos dos alunos surdos não têm sido concretizados, por vários motivos, dentre eles: a falta de políticas públicas voltadas aos surdos (compreendemos a falta mencionada como insuficiência), tanto aqueles que residem em áreas de assentamentos rurais quanto aqueles das áreas urbanas; a não operacionalização das políticas públicas existentes; o investimento insuficiente na formação inicial e continuada de professores e a não efetivação da inclusão nas escolas. Dentre as respostas, duas elucidam bem a questão, a apresentada a seguir evidencia o descaso com os deficientes residentes nas áreas rurais:

Falo com base na minha vivência na área rural, vejo que apesar de estar fundamentado em leis, o acesso aos conhecimentos aos direitos que thes cabe tem sido negado, existe um esquecimento/isolamento destes sujeitos sendo excluídos de várias formas, os lugares as pessoas não estão preparadas para estas situações (EGRESSO 2, 2019).

A fala do egresso evidencia mais do que a questão da exclusão escolar, demonstra a chamada exclusão social, as dificuldades que os sujeitos com algum tipo de deficiência enfrentam cotidianamente, seja quanto ao acesso aos bens sociais ou à acessibilidade arquitetônica. Quanto à população rural, é do nosso conhecimento, conforme trabalhado mais atentamente em Basso (2013), que aqueles que vivem no meio rural ainda precisam lutar por bens sociais já alcançados nas áreas urbanas, como serviços de saúde, escola, áreas de lazer, pavimentação das vias públicas, além da necessidade de deslocamento para escolas urbanas já discutida, fatores que agravam as dificuldades enfrentadas no oferecimento de Educação Especial aos alunos com deficiência, transtornos globais de desenvolvimento e altas habilidades/superdotação.

Para finalizar a pesquisa, indagamos os participantes sobre quais seriam os maiores desafios a serem enfrentados na oferta de Educação Especial para alunos com deficiência auditiva nas escolas do campo. Dentre as problemáticas levantadas, estão as políticas públicas; a estrutura das escolas; a insuficiência na formação docente; a ausência de profissionais que possam auxiliar no processo de inclusão (para além dos pedagogos) e a necessidade de maior conscientização das famílias acerca da escolarização das pessoas com deficiência. A carência geral das escolas do campo fica evidente nas respostas de dois dos participantes, vejamos: 
Sabemos o quanto os sujeitos do campo de modo geral são excluídos dos seus direitos. Quanto às pessoas com deficiência auditiva, os desafios são vários, dentre eles, o próprio acesso à educação/matrícula, a própria escola possuir espaços, recursos adequados para atendêlos e isso vai desde a questão pedagógica, formação de professores, dos próprios alunos e demais funcionários da escola, dentre outros (EGRESSO 2, 2019).

Outro egresso acrescentou que, a falta de preparo dos profissionais que vão para o campo, mesmo sem ter a experiência prática, isso é algo que foi muito debatido durante o curso, além disso muitas vezes as escolas do campo não têm uma estrutura física adequada (EGRESSO 3, 2019).

Relatos que dão-nos indícios da complexidade que permeia a interface entre Educação Especial e Educação do Campo, uma vez que, a efetivação da Educação Especial nas escolas do campo nos parece exigir mais do que a formação docente adequada, visto que requer também a garantia das condições infraestruturais mínimas e de materiais para que a escolarização ocorra.

Nesse sentido, os indicadores coletados e analisados nos sugerem as possibilidades e limites da inclusão da Libras enquanto componente curricular obrigatório nos cursos de formação docente para o campo. A partir do caso analisado, no que diz respeito às possibilidades, os indicadores nos mostraram que a disciplina possibilitou um aporte teórico acerca da Língua Brasileira de Sinais e uma primeira aproximação com ela em termos práticos, além da compreensão de sua importância na formação bilíngue de alunos surdos. Em contrapartida, limitações se evidenciaram na oferta de apenas uma disciplina sobre o tema, que foi oferecida de modo condensado dado o modelo organizacional do curso. De todo modo, defendemos a manutenção da disciplina Libras na grade curricular dos cursos de formação docente e propomos o repensar da maneira que ela tem sido ofertada, de modo que possa garantir aos professores a condição de se comunicar adequadamente com seus alunos com deficiência auditiva.

\section{CONSIDERAÇÕES FINAIS}

Feitas as discussões e apresentação dos resultados da pesquisa, algumas constatações são possíveis, assim como a indicação de maneiras para repensar a oferta de Libras no processo de formação de professores. Iniciamos destacando a necessidade de compreender a interface entre Educação Especial e a Educação do Campo em um contexto de inclusão recente nas agendas públicas, o que faz com que esta relação não esteja consolidada, mas em processo de construção.

Nesse contexto, no que tange ao atendimento dos alunos com deficiência auditiva, os indicadores mostraram que, há uma década, parte significativa destes alunos residentes no campo precisavam ser transportados para as áreas urbanas para ter acesso à escolarização, situação que não se modificou, tendo em vista a tendência de manutenção da política de transporte massivo de alunos do campo para escolas urbanas. Unido a isto, temos a precariedade material, infraestrutural e de preparo docente de parte das escolas do campo, como destacaram alguns dos relatos da pesquisa.

Portanto, a efetivação da política de Educação Especial nas escolas do campo exige, além da formação docente adequada, a garantia de condições mínimas para que o processo de escolarização aconteça. No que diz respeito à formação de professores para o campo, ela obedece a legislação vigente, assim como os demais cursos de Licenciatura e tem ficado à cargo do Programa Nacional de Educação na Reforma Agrária - PRONERA, que tem subsidiado experiências, como a do Curso Especial de Licenciatura em Pedagogia da Terra analisado.

O caso estudado nos permitiu evidenciar a importância da presença da Libras na formação inicial para professores do campo e suas possibilidades, sobretudo no que diz respeito ao aprofundamento dos conhecimentos sobre a Língua Brasileira de Sinais e um primeiro contato com a sua prática. Como aspectos positivos, 
podemos citar a conscientização dos professores em relação ao direito dos alunos com deficiência auditiva serem escolarizados de forma bilíngue, ou seja, utilizando a Libras e a Língua Portuguesa de modo que melhor favoreça o processo de ensino-aprendizagem.

Entretanto, o estudo também apontou para possíveis limites no modo como a Libras aparece na grade curricular dos cursos de formação docente para o campo. Por consistir em apenas uma disciplina, que dada a oferta do curso em alternância, ocorreu de modo condensado, os participantes da pesquisa relataram dificuldades em se apropriar da Libras e sugeriram a ampliação da carga horária da disciplina e a presença da Libras ao longo de todo o curso.

Nesse sentido, a inclusão da Libras na grade curricular dos cursos de formação docente representa uma conquista para aqueles que possuem deficiência auditiva e tem na Língua Brasileira de Sinais sua primeira forma de comunicação. Porém, por todo o exposto, parece-nos que apenas uma disciplina que contemple a temática ao longo de todo o curso de Licenciatura não é suficiente para que os futuros professores se comuniquem em Libras de modo proficiente.

Destarte, cientes da extensão e diversidade dos componentes curriculares que um curso de formação de professores precisa abarcar, consideramos como caminhos possíveis para melhoria na oferta da disciplina "Libras": a ampliação de sua carga horária; a inclusão da Libras como tema transversal nos cursos e sua abordagem em projetos de ensino e extensão, além da necessidade de aprofundamento do estudo da temática nas pesquisas em nível de Graduação e Pós-Graduação. Consideramos que isso colaborará para a formação de professores capazes de colocar em prática os princípios da Educação Especial, tanto em escolas urbanas quanto em escolas do campo.

\section{REFERÊNCIAS}

ALVEZ, C. B.; FERREIRA, J. de P.; DAMÁZIO, M. M. A Educação Especial na Perspectiva da Inclusão Escolar: Abordagem Bilíngue na Escolarização de pessoas com surdez.. Brasília:MEC, 2010. (Coleção Marcos Seesp-Mec, V.4). Disponível em: https://central3.to.gov.br/arquivo/292567/

Acesso em: 23 mar. 2019.
BASSO, J. D. As escolas no campo e as salas multisseriadas no estado de São Paulo: um estudo sobre as condições da educação escolar. 2013. Dissertação (Mestrado em Educação). Universidade Federal São Carlos, São Carlos, 2013.

BRASIL. Casa Civil. Decreto n. 5.626 de 22 de dezembro de 2005. Regulamenta a Lei no 10.436 , de 24 de abril de 2002, que dispõe sobre a Língua Brasileira de Sinais - Libras, e o art. 18 da Lei no 10.098, de 19 de dezembro de 2000. Brasília, 2000. Disponível em: http://www.planalto.gov.br/ccivil 03/ ato20042006/2005/decreto/d5626.htm Acesso em: 23 abr. 2018.

BRASIL. Ministério da Educação. Secretaria de Educação Continuada, Alfabetização, Diversidade e Inclusão - SECADI. Educação do Campo: marcos normativos/Secretaria de Educação Continuada, Alfabetização, Diversidade e Inclusão. Brasília: SECADI, 2012. Disponivel em: http://pronacampo.mec.gov.br/images/pdf/bib edu c campo.pdf Acesso em: 20 mai. 2020.

BRASIL. Ministério da Educação e Cultura. Lei de diretrizes e bases da educação nacional. Brasília, $1996 . \quad$ Disponível em: http://portal.mec.gov.br/seed/arquivos/pdf/tves cola/leis/lein9394.pdf. Acesso em: 05 mai. 2012.

CAIADO, K. R. M.; MELETTI, S. M. F. Educação especial na educação do campo: 20 anos de silêncio no GT 15. Rev. Bras. Ed. Esp., Marília, v. 17, p. 93-104, maio/ago. 2011. Edição Especial. Disponível em: http://www.scielo.br/pdf/rbee/v17nspe1/08.pdf Acesso em: 23 abr. 2018. DOI: 10.1590/S141365382011000400008

CALIXTO, H. R. S. O ensino de Libras na formação de professores: formas de perceber o surdo e a língua de sinais. Revista Interinstitucional Artes de Educar. Rio de Janeiro, v. 4, n. 1, jan./abr. p. 101-116, 2018. Disponível em: file:///C:/Users/msnda/Downloads/30063110388-1-PB.pdf Acesso em: 20 jul. 2020. DOl: $\underline{10.12957 / \text { riae. } 2018.30063}$

CAMACHO, R. S. O Programa Nacional de Educação na Reforma Agrária (Pronera): uma política pública de educação do campo. Colloquium Humanarum, Presidente Prudente, v. 
12, n. 2, p. 119-127, abr./jun. 2015. Disponível em:

http://revistas.unoeste.br/index.php/ch/article/v iew/1231/1393 Acesso em: 01 set. 2020. DOI: 10.5747/ch.2015.v12.n2.h210

GAMBOA, S. S. Quantidade-Qualidade: para além de um dualismo técnico e de uma dicotomia epistemológica. In: GAMBOA, S. S. (Org.); SANTOS FILHO, C. dos. Pesquisa educacional: quantidadequalidade. 7. ed. São Paulo: Cortez, 2009. p. 84110.

LAKATOS, E. M.; MARCONI, M. de A. Fundamentos de metodologia científica. 5. ed. São Paulo: Atlas, 2003.

LOUZADA, J. C. de A.; MARTINS, S. E. S. de O.; GIROTO, C. R. M. A disciplina Libras na formação de professores: desafios para a formulação de espaços educacionais bilíngues. Práxis Educativa, Ponta Grossa, v. 12, n. 3, p. 864-886, set./dez. 2017. Disponível em: https://www.revistas2.uepg.br/index.php/praxisedu cativa Acesso em: 20 jul. 2020. DOl: 10.5212/PraxEduc.v.12i3.010

MENDES, E. G. Inclusão marco Zero: começando pelas creches. Araraquara-SP: Junqueira\&Marin editores, 2010.

NERES, C. C.; KASSAR, M. C. M. Inclusão escolar de crianças com deficiência: do direito à matrícula ao acesso ao conhecimento em trajetórias escolares. International Studies on Law and Education., v.22, p. 39-50, jan./abr. 2016.

MOLINA, M. C. Contribuições das Licenciaturas em Educação do Campo para as políticas de formação de educadores. Educ. Soc., Campinas, v. 38, n. 140, p. 587-609, jul./set. 2017. Disponível em: https://www.scielo.br/pdf/es/v38n140/16784626-es-38-140-00587.pdf Acesso em: 01 set. 2020. DOI: $10.1590 /$ es0101-73302017181170

PRONERA. Programa Nacional de Educação na Reforma Agrária. Manual de Operações. Brasília, DF: 2016. 145 p. Disponível em: http://www.incra.gov.br/sites/default/files/uploa ds/reforma-agraria/projetos-eprogramas/pronera/manual pronera 18.01.16.pdf Acesso em: 01 set. 2020.
ROSSI, R. A. A Libras como disciplina de Libras no Ensino Superior. Revista de Educação, ValinhosSP, v. 13, n. 15, p. 71-85, 2010. Disponível em: http://www.pgsskroton.com.br/seer/index.php/e duc/article/viewFile/1867/1772 Acesso em: 23 abr. 2018.

SANTOS, C. A. dos. Programa Nacional de Educação na Reforma Agrária (PRONERA). In: CALDART, R. S. (Org.) et. al. In: Dicionário de Educação do Campo. Rio de Janeiro: Escola Politécnica de Saúde Joaquim Venâncio; São Paulo: Expressão Popular, 2012. p. 578- 586.

SILVA, L. H. Concepções e práticas de alternância em educação do campo. Nuances: estudos sobre educação, Presidente Prudente, v. 17, n. 18 jun. p. 180-192, 2010. Disponível em: https://revista.fct.unesp.br/index.php/Nuances/a rticle/view/760 Acesso em: 01 set. 2020. DOl: $\underline{10.14572 / \text { nuances.v17i18.760 }}$

UNIVERSIDADE FEDERAL DE UNIVERSIDADE FEDERAL DE SÃO CARLOS. Projeto Político Pedagógico do Curso Especial de Licenciatura em Pedagogia da Terra. UNIVERSIDADE FEDERAL DE SÃO CARLOS/SP: UFSCar, 2014. 165 p. 